\title{
THE EFFECT OF THE MEDIUM AND SOURCE OF GROWTH FACTORS ON THE SATELLITISM TEST FOR HAEMO- PHILUS SPECIES
}

\author{
Nora M. Evans and D. D. SMITH \\ Bacteriology Laboratory, The Prince of Wales Hospital, \\ Randwick, New South Wales, Australia
}

Even the earliest reports of Pfeiffer's bacillus stressed its peculiar ability to form large colonies in the vicinity of other bacteria, yeasts and fungi growing on blood agar (Davis, 1921a). This phenomenon of satellitism remains the most important method for the identification of Haemophilus influenzae. In the test, as first described by Davis (1921b), a peptone blood agar plate, seeded evenly with the strain under examination, was inoculated from a colony of a staphylococcus. By this means the two essential growth factors were made available, the $X$ factor in the blood-later identified as haemin or related porphyrins (Fildes, 1921) - and the V factor-nicotinamide adenine dinucleotide or NAD (Lwoff and Lwoff, 1937)—produced by the staphylococcus.

Subsequently a similar and closely related organism requiring $\mathrm{V}$ but not $\mathrm{X}$ factor was described by Rivers (1922) and named $H$. parainfluenzae. A second plate of nutrient agar containing no added blood was therefore included in the test to allow the distinction to be made between $H$. influenzae, requiring both $\mathrm{X}$ and $\mathrm{V}$ factors and capable of satellitism on the blood agar only, and $H$. parainfluenzae which does not require blood.

It is known that certain variables affect the reliability of the test, particularly as regards the X factor requirement (Smith, Hale and O'Callaghan, 1953; Koser, 1968). For example, strains of $H$. influenzae may appear on some nutrient media to have no $\mathrm{X}$ requirement, an error attributable to traces of haemin compounds carried over in a heavy inoculum or already present in the medium (Zinnemann, 1960; Biberstein and Gills, 1961; Turk and May, 1967). Under these conditions some strains would be wrongly identified as $H$. parainfluenzae.

In addition, we have noted, as did Butler (1962a), that nutritional differences between the two species are not confined to the requirement for $\mathrm{X}$ and $\mathrm{V}$ factors. We have observed that certain strains of $H$. parainfluenzae fail to grow on some media that support the growth of $H$. influenzae. For the recognition of the species, the satellitism test therefore requires that the nutrient agar used be not only free of haemin compounds but should otherwise satisfy the growth requirements of both species.

This paper examines the effect of different media and sources of $\mathrm{X}$ factor in determining the $\mathrm{X}$ and $\mathrm{V}$ requirements of freshly isolated and type culture strains of $H$. influenzae and $H$. parainfluenzae.

Received 6 Mar. 1972; accepted 13 Apr. 1972.

J. MED. MICROBIOL.-VOL. 5 (1972) 


\section{MATERIALS AND METHODS}

Media. Chocolate agar was prepared (Cruickshank, 1965) from Trypticase Soy Agar (BBL) with 7.5 per cent. horse blood. The organisms were isolated on a selective medium of Nutrient Broth no. 2 (Oxoid), containing 1.0 per cent. fresh yeast extract, 0.25 per cent. lysed horse red blood cells, 2.5 units of bacitracin per $\mathrm{ml}$ and 1.0 per cent. Ionagar no. 2 (Oxoid). For the determination of $\mathrm{X}$ and $\mathrm{V}$ growth-factor requirements, four different types of nutrient agar were used: (1) Nutrient Broth no. 2 (Oxoid), with 1.0 per cent. Ionagar no. 2 (referred to as nutrient agar no. 2), (2) Proteose Peptone Broth (Difco) with 0.6 per cent. $\mathrm{NaCl}$ (Gilder and Granick, 1947) and 1.0 per cent. Ionagar (referred to as proteose peptone agar), (3) yeast extract agar (Zinnemann, 1960) and (4) proteose peptone agar with the addition of $4.84 \mathrm{mg}$ of sodium oleate and $1 \mathrm{mg}$ of thiamin per litre. $\mathrm{X}$ factor was provided in the medium as 7.5 per cent. horse blood or as haemin, $20 \mu \mathrm{g}$ per ml.

Organisms. Eighty strains were examined, of which nine were reference strains: $H$. influenzae no. NCTC4560 (unencapsulated), NCTC8469 (type c), NCTC8470 (type d), NCTC8472 (type e), NCTC8473 (type f) and H. parainfluenzae no. NCTC4101, NCTC10665, ATCC7901 and ATCC9796. The remaining 71 strains, including five $H$. influenzae encapsulated members of type $b$, were freshly isolated from cerebrospinal fluid, sputum, throat and eye swabs on the enriched, selective medium. Primary isolates of iridescent and noniridescent colonies of Gram-negative rods resembling Haemophilus were plated on chocolate agar to obtain pure cultures. The strains were preserved on chocolate agar slopes and in liquid nitrogen for further study. All cultures were incubated at $37^{\circ} \mathrm{C}$ in an atmosphere of 5 per cent. $\mathrm{CO}_{2}$ in air $(\mathrm{v} / \mathrm{v})$. Iridescent strains were examined for agglutination and capsule swelling with $H$. influenzae antisera types a-f (Burroughs Wellcome).

Chemicals and growth factors. The stock solution of NAD ( $\beta$-diphosphopyridine nucleotide, Sigma Chemical Co. Ltd) contained $1000 \mu \mathrm{g}$ per ml dissolved in glass-distilled water. Haemin (Koch-Light) was prepared as described by Turk and May at a concentration of $2000 \mu \mathrm{g}$ per ml. Both solutions were sterilised by means of a Swinnex $0 \cdot 45 \mu$ Millipore filter unit. Yeast extract was prepared from fresh baker's yeast (Lwoff and Lwoff). Thiamin hydrochloride (E. Merck), also sterilised by filtration, was used at a final concentration of $1 \mathrm{mg}$ per litre and sodium oleate, sterilised at $15 \mathrm{lb}$. for $15 \mathrm{~min}$., at a final concentration of $4.84 \mathrm{mg}$ per 1 (Butler, 1962a).

Determination of $X$ and $V$ requirements on different nutrient agars. Two plates of each of the four types of nutrient agar, one set containing $X$ factor and the other set without, were inoculated with a suspension of organisms from a $24-\mathrm{hr}$ chocolate agar culture. The technique varied slightly from that of Zinnemann et al. (1968) in that the suspension was in phosphatebuffered saline and contained approximately $10^{7}$ viable organisms per $\mathrm{ml}$. A standard loopful of organisms $(0.01 \mathrm{ml})$ was spread evenly over one-half of each plate. Two sources of $\mathrm{V}$ factor were then added to all the plates: (1) a colony of staphylococcus (Oxford strain, Commonwealth Serum Laboratories) and (2) a 6-mm Whatman paper disk containing approximately $4 \mu \mathrm{g}$ NAD. Growth when present was semi-confluent and consisted of colonies ranging from 0.5 to $1.5 \mathrm{~mm}$ in diameter at $18 \mathrm{hr}$.

The strains were classified according to accepted practice (Zinnemann, 1960; Cowan and Steel, 1965). Strains requiring X factor alone were expected to grow over the entire inoculated area of the plate containing $X$ factor, while on the same medium strains dependent on $V$ alone, or both $\mathrm{X}$ and $\mathrm{V}$, were expected to show satellite growth only beside the source of NAD. On the medium without $\mathrm{X}$ factor, only strains requiring $\mathrm{V}$ factor alone show satellite growth.

\section{RESULTS}

All the 80 strains tested required V factor and were dependent on purified NAD for satellite growth on proteose peptone blood agar. However, it was found that the apparent requirements for $\mathrm{X}$ and $\mathrm{V}$ factors could be influenced both by the source of the $\mathrm{X}$ factor and by the type of medium employed. 
The effect of blood or haemin as the source of X factor

The table summarises the results obtained. On proteose peptone agar, with blood as the source of $\mathrm{X}$ factor, 54 strains required both $\mathrm{X}$ and $\mathrm{V}$ factors, whereas the remaining 26 strains needed only the $V$ factor. When haemin was substituted for blood as the source of X factor, 11 of the 54 strains that had previously appeared to require both $\mathrm{X}$ and $\mathrm{V}$ factors now failed to grow. However, the same 11 strains grew in the absence of blood or haemin in the vicinity of a disk containing NAD on proteose peptone agar containing sodium oleate. Thus on proteose peptone agar containing oleate, the number of strains

TABLE

The effect of the medium and the source of $X$ factor on the determination of $X$ and $V$ requirements of 80 strains of Haemophilus species

\begin{tabular}{|c|c|c|c|c|}
\hline \multirow{2}{*}{$\begin{array}{l}\text { Source of } \\
\mathrm{X} \text { factor }\end{array}$} & \multirow{2}{*}{ Medium } & \multicolumn{3}{|c|}{$\begin{array}{l}\text { Number of strains with } \\
\text { apparent growth requirement }\end{array}$} \\
\hline & & $\begin{array}{l}\text { for } \\
\mathrm{V} \text { factor } \\
\text { only }\end{array}$ & $\begin{array}{c}\text { for } \\
X \text { and } V \\
\text { factors }\end{array}$ & Indeterminate \\
\hline $\begin{array}{l}\text { Horse blood } \\
\text { Haemin } \\
\text { Haemin }\end{array}$ & $\begin{array}{l}\text { Proteose peptone } \\
\text { Proteose peptone } \\
\text { Proteose peptone } \\
\quad \text { +oleate }\end{array}$ & $\begin{array}{l}26 \\
26 \\
37\end{array}$ & $\begin{array}{l}54 \\
43 \\
43\end{array}$ & $\begin{array}{r}0 \\
11 \\
0\end{array}$ \\
\hline Haemin & $\begin{array}{l}\text { Nutrient agar } \\
\text { no. } 2\end{array}$ & 51 & 27 & 2 \\
\hline
\end{tabular}

dependent on both $\mathrm{X}$ and $\mathrm{V}$ factors was 43 and the number of strains requiring the $\mathrm{V}$ factor only was 37 as compared with 26 on proteose peptone agar itself. Yeast extract gave similar results to proteose peptone agar, but growth on yeast extract agar was less abundant, with colonies less than $0.5 \mathrm{~mm}$ in diameter.

Growth of V-dependent strains on proteose peptone agar was improved by the addition of thiamin, with colonies approximately $1.5 \mathrm{~mm}$ in diameter.

\section{The effect of the medium}

The influence of the medium on the determination of $\mathrm{X}$ and $\mathrm{V}$ requirements is shown in the table. When the satellitism test was performed with haemin as the source of $\mathrm{X}$ on nutrient agar no. 2, only 27 strains appeared to require both $\mathrm{X}$ and $\mathrm{V}$ factors, compared with 43 that showed the same requirements when proteose peptone with oleate was used, i.e., a difference of 16 strains. It was also noted that on nutrient agar no. 2 these 16 strains formed larger colonies $(>1.0 \mathrm{~mm}$ diameter) around the staphylococcus than those beside the disk containing NAD $(<0.5 \mathrm{~mm}$ diameter).

In addition, when nutrient agar no. 2 was used, ten of the V-dependent strains grew poorly and two strains failed to grow. The addition of thiamin 
to this medium supported the growth of all 12 of these strains. The $11 \mathrm{~V}$ dependent strains that failed to grow on proteose peptone or yeast extract agar without oleate did not require this additive on nutrient agar no. 2 .

\section{DisCUSSION}

Strains of $H$. influenzae identified serologically have been observed to grow occasionally with a source of NAD on media containing no added $\mathrm{X}$ factor (Cooper and Attenborough, 1968; Klein and Blazevic, 1969). This has been explained on the theory that certain meat infusion media contain sufficient haeme compounds to support visible growth of some strains of $H$. influenzae (Zinnemann, 1960; Biberstein and Gills, 1961; Koser, 1968). In the present study, 16 strains of $H$. influenzae appeared to be dependent only on $\mathrm{V}$ factor when grown on nutrient agar no. 2 (Oxoid Nutrient Broth no. 2 with Ionagar) which contains meat extract; on proteose peptone agar each of these strains was X-and V-dependent. Of the strains showing this nutritional pattern, four were freshly isolated encapsulated type $\mathrm{b}$ strains and another four were reference strains of $H$. influenzae, namely no. NCTC4560, NCTC8470, NCTC8472 and NCTC8473. It was observed, however, that on nutrient agar no. 2, satellite growth was more profuse around the colony of the staphylococcus than beside a disk containing purified NAD. This may be explained by the production of catalase by staphylococci, which has been shown to replace haeme in the nutrition of $H$. influenzae (Pickett and Stewart, 1953; Brumfitt, 1959). From this evidence and other published studies (Gilder and Granick, 1947; Rogers, Zinnemann and Foster, 1960; Butler, 1962b) it is clear that media free from haeme, such as proteose peptone agar or yeast extract agar, must be employed in the determination of $\mathrm{X}$ factor requirements of Haemophilus species.

We have found that 11 of $37 \mathrm{~V}$-dependent strains required both $\mathrm{V}$ and a factor in horse blood replaceable by sodium oleate, but not by haemin. Their failure to grow on proteose peptone agar without blood suggested a requirement for both $\mathrm{X}$ and $\mathrm{V}$ and on these grounds they would mistakenly be identified as $H$. influenzae. However, their ability to produce satellite colonies around a disk containing NAD on proteose peptone or yeast extract agars containing sodium oleate confirmed their identity as $H$. parainfluenzae, dependent on $\mathrm{V}$ but not X factor. Possibly sodium oleate serves both a metabolic and an absorptive function (Butler, 1962a) and in the latter respect may, like albumin, detoxify fatty acids or other inhibitory agents. A further requirement of other V-dependent strains on nutrient agar no. 2 was thiamin, a vitamin frequently destroyed in the preparation of laboratory media (Bridson and Brecker, 1970); on this medium without additional thiamin, ten strains grew poorly and two failed to grow. Proteose peptone agar was also thiamin deficient.

Holt (1961) found that a nutrient agar consisting of Oxoid Nutrient Broth no. 2 with $\mathrm{X}, \mathrm{V}$ and other growth factors including uracil, hypoxanthine and cysteine, promoted luxuriant growth of Haemophilus species. The possible content of haeme compounds in the nutrient broth, however, renders such a medium unsuitable for satellitism tests. On the other hand, nutrient agars 
such as proteose peptone and yeast extract avoid this problem, but may introduce further fallacies unless supplemented with other essential growth factors.

\section{SUMMARY}

Three types of nutrient agar were examined for their suitability in determining the $\mathrm{X}$ and $\mathrm{V}$ requirements of Haemophilus influenzae and $H$. parainfluenzae. The 80 strains tested were either from type culture collections or freshly isolated. Twenty-six strains required $\mathrm{V}$ factor only and 54 both $\mathrm{X}$ and $\mathrm{V}$ factors when proteose peptone agar was employed with blood as a source of $\mathrm{X}$. On a nutrient agar prepared from Oxoid Nutrient Broth no. 2, when haemin was used as the source of $\mathrm{X}$ factor the distribution was almost exactly reversed; 51 strains appeared to be V-dependent and only $27 \mathrm{X}$ - and Vdependent. When tests were carried out on proteose peptone agar with added sodium oleate and thiamin (a medium providing essential growth requirements for Haemophilus with the exception of $\mathrm{X}$ and $\mathrm{V}$ factors), 43 strains were $\mathrm{X}$ and $\mathrm{V}$ dependent and 37 dependent on $\mathrm{V}$ only. The use of this last medium for satellitism tests is suggested.

We wish to acknowledge with gratitude the advice received from Dr S. M. Bell on the conduct of these studies and the writing of this paper.

\section{REFERENCES}

Biberstein, E., AND Gills, Marjorie 1961. Catalase activity of Haemophilus species grown with graded amounts of hemin. J. Bact., 81, 380.

BRIDSON, E. Y., AND BRECKER, A. 1970. In Methods in microbiology, edited by J. R. Norris and D. W. Ribbons, London, vol. 3A, pp. 245 and 250.

Brumfirt, W. 1959. Some growth requirements of Haemophilus influenzae and Haemophilus pertussis. J. Path. Bact., 77, 95.

ButLER, L. O. 1962a. A defined medium for Haemophilus influenzae and Haemophilus parainfluenzae. J. Gen. Microbiol., 27, 51.

ButLer, L. O. 1962b. A haematin-independent mutant of Haemophilus influenzae. J. Gen. Microbiol., 29, 189.

Cooper, R. G., AND ATrenborough, I. D. 1968. An indicator method for the detection of bacterial X and V factor dependence. Aust. J. Exp. Biol. Med. Sci., 46, 803.

Cowan, S. T., AND Steel, K. J. 1965. Manual for the identification of medical bacteria, Cambridge, p. 165.

Cruickshank, R. 1965. Medical microbiology, 11th ed., London, p. 746.

DAvis, D. J. 1921a. The accessory factors in bacterial growth. IV. The "satellite" or symbiosis phenomenon of Pfeiffer's bacillus (B. influenzae). J. Infect. Dis., 29, 178.

Davis, D. J. 1921b. The accessory factors in bacterial growth. V. The value of the satellite (or symbiosis) phenomenon for the classification of hemophilic bacteria. J. Infect. Dis., 29, 187.

Fildes, P. 1921. The nature of the effect of blood-pigment upon the growth of $B$. influenzae. Br. J. Exp. Path., 2, 16.

Gilder, H., AND Granick, S. 1947. Studies on the Hemophilus group of organisms. Quantitative aspects of growth on various porphin compounds. J. Gen. Physiol., 31, 103.

Holt, L. B. 1961. The growth-factor requirements of Haemophilus influenzae. J. Gen. Microbiol., 27, 317.

Klein, Marilyn, ANd Blazevic, Donna J. 1969. Differentiation of Haemophilus species using satellite methods. Amer. J. Med. Technol., 35, 695. 
Koser, S. A. 1968. Vitamin requirements of bacteria and yeasts, Springfield, Illinois, p. 282. LwOFF, A., AND LwOFF, MARGUERITE 1937. Studies on codehydrogenases. I. Nature of growth factor "V". Proc. Roy. Soc. B., 122, 352.

PicketT, M. J., AND Stewart, R. M. 1953. Identification of hemophilic bacilli by means of the satellite phenomenon. Amer. J. Clin. Path., 23, 713.

RIVERs, T. M. 1922. Influenza-like bacilli. Growth of influenza-like bacilli on media containing only an autoclave-labile substance as an accessory food factor. Bull. Johns Hopkins Hosp., 33, 429.

Rogers, K. B., ZINNEMANN, K., AND Foster, W. P. 1960. The isolation and identification of Haemophilus spp. from unusual lesions in children. J. Clin. Path., 13, 519.

Smith, W., Hale, J. H., and O'Callaghan, Cynthia H. 1953. Haem utilisation and nitrate reduction by Haemophilus influenzae. J. Path. Bact., 65, 229.

TURK, D. C., AND MAY, J. R. 1967. Haemophilus influenzae, its clinical importance, London, pp. 11 and 116.

ZINNEMANN, K. 1960. Haemophilus influenzae and its pathogenicity. Ergebn. Mikrobiol. ImmunForsch exp. Ther., 33, 307.

Zinnemann, K., Rogers, K. B., Frazer, Joyce, and Boyce, J. M. H. 1968. A new Vdependent Haemophilus species preferring increased $\mathrm{CO}_{2}$ tension for growth and named Haemophilus paraphrophilus, Nov. Sp. J. Path. Bact., 96, 413. 